\title{
4
}

\section{Modeling and Simulation of Thermoelectric Energy Harvesting Processes}

\author{
Piotr Dziurdzia \\ AGH University of Science and Technology in Cracow \\ Poland
}

\section{Introduction}

Thermoelectric modules are becoming more and more popular nowadays again as their prices are going down and the new potential applications have appeared due to recent developments in microelectronic and wireless technology. Not so long ago Peltier modules were mainly used as thermoelectric coolers TECs, for example in thermal image generator (De Baetselier et al., 1995a), thermoelectrically cooled radiation detectors (Anatychuk, 1995), active heat sinks for cooling of microstructures and microprocessors (Dziurdzia \& Kos, 2000), fiber optic laser packages (Redstall \& Studd, 1995), special medical and laboratory equipment for temperature regulation (Uemura, 1995), etc. Also in some niche applications, thermoelectric modules working as thermoelectric generators TEGs have been used for some time. Among others, the examples include a miniature nuclear battery for space equipment (Penn, 1974) and remote power stations (McNaughton, 1995).

Fulfilment of the new paradigm Internet of Things (Luo et al., 2009) relating to the idea of ubiquitous and pervasive computing as well as rapid development of wireless sensor networks WSN technologies have attracted recently a great research attention of many R\&D teams working in the area of autonomous sources of energy (Paradiso \& Starner, 2005), (Joseph, 2005). Apart from light and vibrations, heat energy and thermoelectric conversion are playing an important role in the field of energy harvesting or energy scavenging.

As a rule, thermoelectric generators suffer from relatively low conversion efficiency (not exceeding $12 \%$ ), so they are practically not applicable to large-scale systems, not to mention power stations. On the other hand they seem to be promising solutions when they are used to harvesting some waste heat coming from industry processes or central heating systems.

In recent years a lot of attention was paid to analyzing Peltier modules and efficiency of thermal energy conversion into electrical one (Beeby \& White, 2010), (Priya \& Inman, 2009).

Now, many research teams are striving for development of complete autonomous devices powering WSN nodes. Since low power integrated circuits, like microcontrollers, transceivers and sensors, have been commonly available for several years the efforts are focused nowadays especially on ambient energy scavenging and emerging technologies in the field of ultra low voltage conversion, energy storing and efficient power management (Salerno, 2010). There are solutions already reported, operating from extremely low voltages 
about tens of $\mathrm{mV}$ resulting from very small temperature gradients, equaling to single Celsius degrees. In fact, some presented prototypes could be supplied from energy easily available even from human body heat, for example a sensor application (Mateu et al., 2007) and wristwatch (Kotanagi et al., 1999).

Lack of dedicated tools covering complex simulations of thermoelectric devices in both thermal and electrical domains prompted many research teams into developing of original models of Peltier elements facilitating analysis and design of thermoelectric coolers (Lineykin \& Ben-Yaakov, 2005), (Dziurdzia \& Kos, 1999), (Wey, 2006) as well as thermoegenerators (Chen et al., 2009), (Freunek et al., 2009).

The goal of this text is to show viability of modelling of complex phenomena occurring in thermoelectric devices during energy harvesting as well as coupled simulations both thermal and electrical processes by means of electronic circuits simulators.

Among other benefits such as the low cost, easy to learn notation and built-in procedures for solving differential and nonlinear equations, the electronic circuit SPICE-like simulators have one a very important advantage, namely they are very intuitively understood by electronic engineers community and can be easily used for simulation of other that electrical phenomena. So, the modeling, programming and simulations can be done very fast and in this sway facilitating work of designers. By means of SPICE, provided that a reliable electrothermal model of a Peltier module is available, the energy conversion and distribution flow can be simulated in an autonomous sensor node that is shown in Fig. 1.

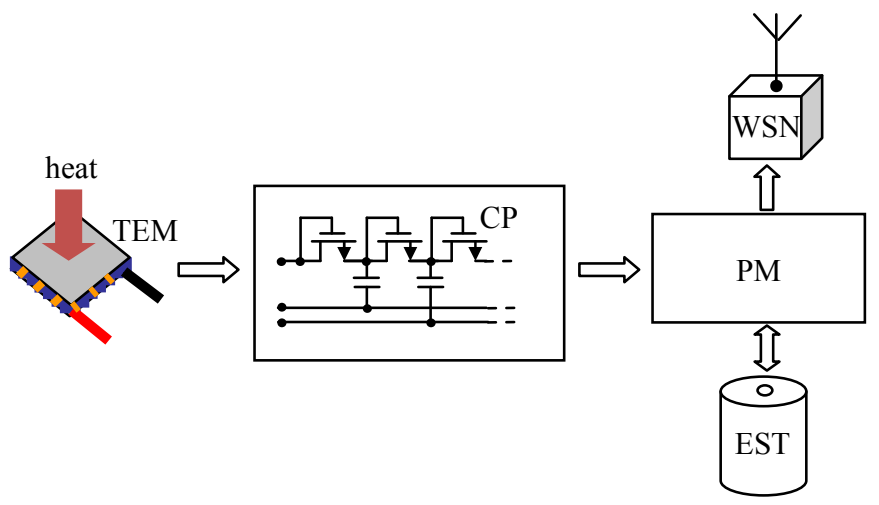

Fig. 1. Thermoelectric energy conversion and distribution flow in an autonomous WSN.

Electric power is produced by a temperature difference between the ambient and the hot surface of a thermoelectric module TEM heated by a waste heat coming from industrial processes, geothermal, isotopic, burned fossil fuels or even human warmth. After that, the generated low voltage is boosted up in a DC/DC converter or a charge pump CP. Next, in power management unit PM the available energy is distributed between autonomous wireless sensor node WSN and the energy storage EST.

A key concern, when designing TEGs for energy harvesters, is not the efficiency but the maximum power transfer to the load. Therefore it is very essential to perform - prior to 
physical design - series of simulation experiments for different scenarios in order to extract as much as possible electrical power. The presented model is useful in forecasting the operation of TEGs under different conditions relating to temperature as well electrical domains. Even with the best DC/DC converter boosting up the voltage to supplying an electronic circuitry one has to remember that the thermoelectric energy harvesting is a low efficiency method and there is not much power available. Therefore a lot of effort should be invested in simulation and design stage of energy harvesters based on Peltier modules.

In the next following paragraphs basics of thermoelectric modules based on Peltier devices are shown, with the phenomena that rule their operation and are crucial for comprehensive understanding of heat to electric energy conversion. After that an analytical description of the heat flux and power generation in TEMs is presented, followed by electrothermal modelling in electronic circuit simulator. At the end a set of simulations scenarios for thermogenerator based on a commercially available thermoelectric module is shown. The results of simulations experiments are very useful in predicting maximum ratings of the TEGs during operation under different ambient conditions and electrical loads.

\section{Basics of thermoelectric generators}

Thermoelectric generator TEG is a solid-state device based on a Peltier module, capable of converting heat into electrical energy. In the opposite mode of work when it is supplied with DC current it is able to pump heat, which in consequence leads to cooling one of its sides whereas heating of the other The Peltier module consists of $\mathrm{N}$ pairs of thermocouples connected electrically in series and thermally in parallel. They are sandwiched between two ceramic plates which are well conducting heat but on the other hand representing high electrical resistance (Fig. 2).

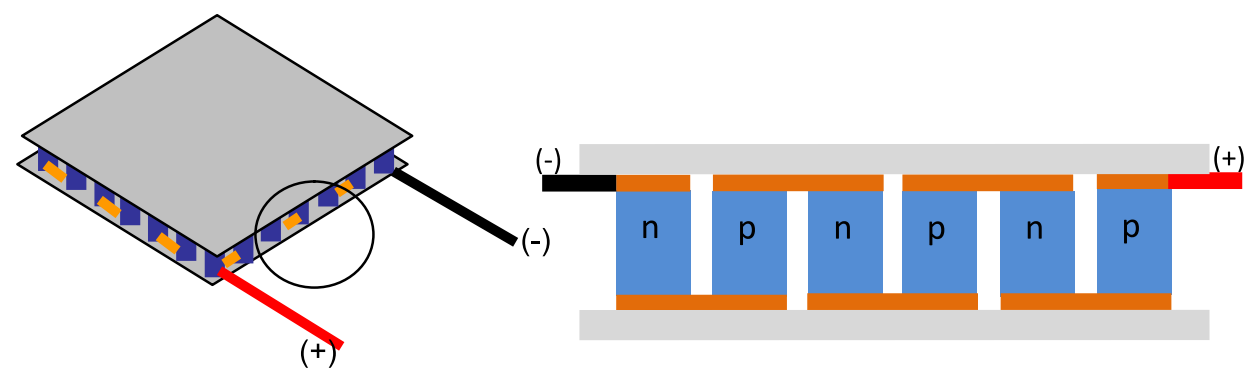

Fig. 2. Thermoelectric module.

Thermoelectric material is characterized by the figure of merit $Z$ which is a measure of its suitability for thermoelectric applications (1). Good materials should have high Seebeck coefficient $a$, low electrical resistivity $\rho$ and low thermal conductivity $\lambda$.

$$
Z=\frac{\alpha^{2}}{\rho \lambda}
$$


The most commonly used thermocouples in modules are made of heavily doped bismuth telluride $\mathrm{Bi}_{2} \mathrm{Te}_{3}$. They are connected by thin copper strips in meander shape and covered by two alumina $\mathrm{Al}_{2} \mathrm{O}_{3}$ plates.

The overall operation of a TEG is governed by five phenomena, i.e.: Seebeck, Peltier, Thomson, Joule and thermal conduction in the materials. Some of them foster thermoelectric conversion but a few of them limit the TEG performance.

\subsection{Seebeck effect}

Seebeck Effect describes the induction of a voltage $V_{S}$ in a circuit consisting of two different conducting materials, whose connections are at different temperatures. In case of a Peltier module the Seebeck voltage can be expressed as in (2), where $T_{h}-T_{c}$ is the temperature gradient across the junctions located at the opposite sides of the module.

$$
V_{S}=\alpha\left(T_{h}-T_{c}\right)
$$

\subsection{Peltier effect}

Peltier phenomenon describes the processes occurring at the junction of two different conducting materials in the presence of a flowing electrical current. Depending on the direction of current flow the junction absorbs or dissipates heat to the surroundings. The amount of absorbed or dissipated heat is proportional to the electrical current and the absolute temperature $T$. The heat power associated with the Peltier phenomenon can be calculated as in (3),

$$
Q_{P}=\pi I=\alpha T I
$$

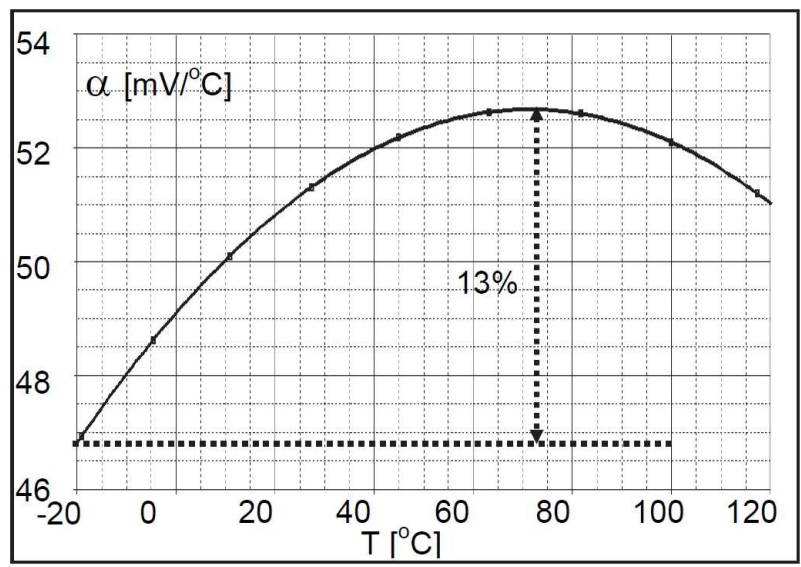

Fig. 3. Seebeck coefficient against temperature.

where $I$ is the electrical current flowing in the thermoelectric module, $\pi$ is the Peltier coefficient that can be expressed by means of Seebeck coefficient $a$. For bismuth telluride, Seebeck coefficient is not constant but slightly temperature dependent. In Fig. 3, function of 
the Seebeck coefficient against temperature, for a commercially available thermoelectric module is shown.

Peltier effect is the basis of the thermoelectric coolers, while the Seebeck effect is used in electrical power generators.

\subsection{Thomson effect}

Thomson phenomenon takes place in presence of an electrical current flowing not through a junction of two materials as in Peltier effect but in a homogeneous electrical conductor placed between objects at two different temperatures. Depending on the direction of current flow, a heat is absorbed or dissipated from the conductor volume. For instance, if the electrons are the current carriers and move towards higher temperatures, in order to maintain thermal equilibrium they must take an energy as heat from the outside. The reverse situation occurs in the opposite direction of the current flow. Quantitative model of this effect is described by (4) (Lovell et al., 1981),

$$
Q_{t}=-\mu_{T} \cdot I \cdot \frac{d T}{d x}
$$

where $\mu_{T}$ is the Thomson coefficient.

The influence of Thomson effect on performance of thermoelectric devices is very weak, however it exists and cannot be neglected for very high temperature gradients.

\subsection{Joule heat phenomenon}

Joule heat generation is the most commonly known phenomena associated with a current flowing in electrical circuits. Opposite to the previously described phenomena, Joule effect is not reversible and it manifests in a heat dissipated by material with non-zero resistance in the presence of electrical current (5).

$$
Q_{j}=I^{2} \cdot R
$$

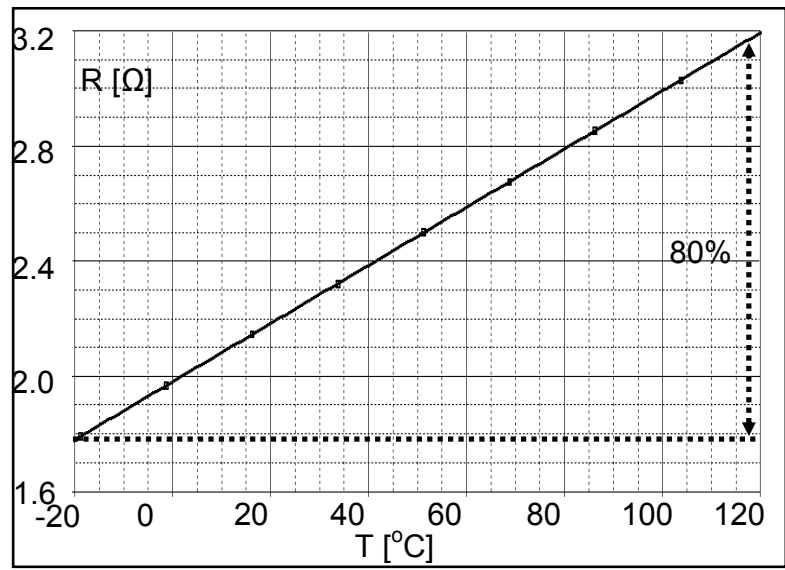

Fig. 4. Internal resistance of a thermoelectric module against temperature. 
In Fig. 4, a temperature function of the internal resistance of a thermoelectric module is shown.

\subsection{Heat conduction}

Heat flow and conduction between two sides of a thermoelectric module is described in details in the next paragraph. An important difficulty in describing this phenomenon in the case of Peltier modules is a significant temperature difference across the active material of $\mathrm{Bi}_{2} \mathrm{Te}_{3}$ and more over the strong temperature dependence of the thermal conductivity $K$, as shown in Fig. 5.

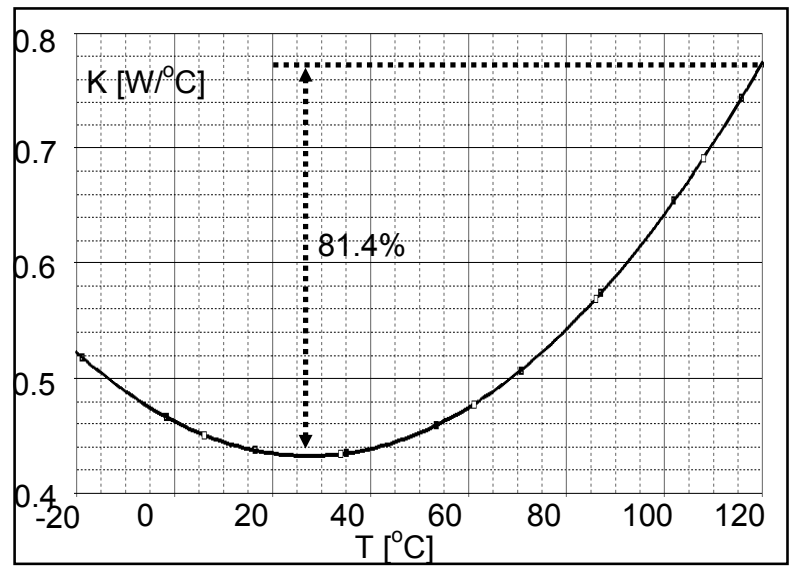

Fig. 5. Thermal conductivity of a thermoelectric device against temperature.

\subsection{Power generation}

When a thermoelectric couple or a meander of serially connected pairs is placed between two objects at two different temperatures $T_{c}$ and $T_{h}$ - e.g. a heat sink and a heat source - it can produce Seebeck voltage $V_{S}$ (Fig. 6). In this case only Seebeck effect and heat conduction phenomenon occur.

If the electromotive force $V_{S}$ is closed by a resistive load $R_{L}$ then an electrical power $P$ is generated (6) and the thermoelectric module is utilizing all the described phenomena.

$$
P=I^{2} R_{L}=\left(\frac{V_{S}}{R_{L}+R_{I}}\right)^{2} R_{L}=\left(\frac{\alpha\left(T_{h}-T_{c}\right)}{R_{L}+R_{I}}\right)^{2} R_{L}
$$

Where, $R_{I}$ is the internal resistance of the thermoelectric couples made of bismuth telluride.

\subsection{Benefits of thermoelectric generators}

Thermoelectric modules manifest some advantages when the other harvesting methods and sources of energy coming from the environment are considered. First of all, thermoelectric generation is some kind of solid state power conversion. Therefore the Peltier devices do not 
have any moving parts, so they are reliable, silent and they are characterized by very long MTF (mean time to failure). Moreover they are not chemically hazardous. Next, opposite to photovoltaic panels they can operate in conditions where there light is not sufficient or not available at all. Finally, temperature gradients have tendency to change rather more slowly than the amplitudes of vibrations which often are occurring as single bursts. Therefore, thermoelectric generators can provide energy in a continuous way.

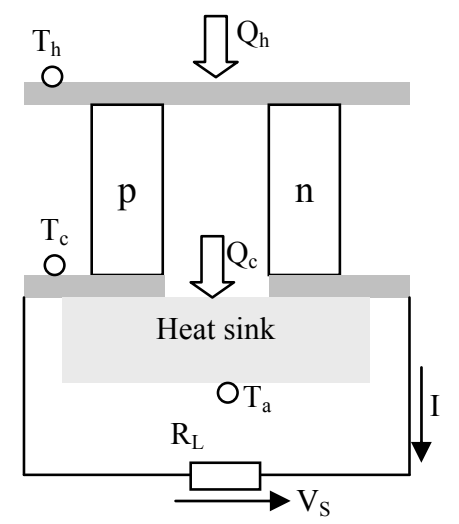

Fig. 6. Power generation by a single thermocouple exposed to a temperature gradient.

\section{Analytical analysis of thermoelectric devices}

During considerations on modeling of thermoelectrical energy processes generation one has to take into account electrothermal interactions between a few phenomena that form a feedback loop as depicted in Fig. 7.

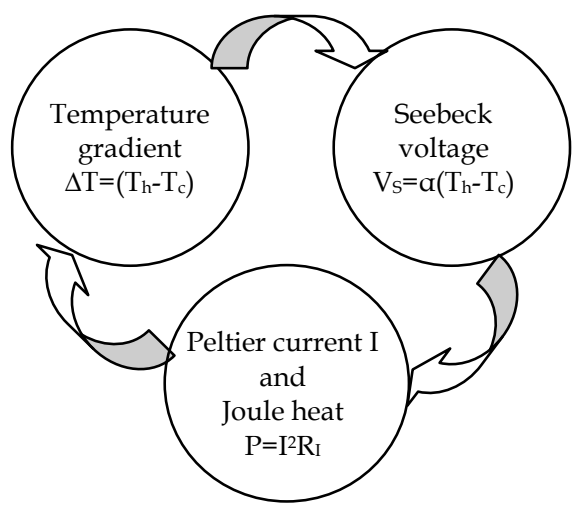

Fig. 7. Electrothermal interactions in thermoelectric modules working as TEGs.

A temperature gradient $\Delta T$ resulting from different ambient conditions between two sides of Peltier module causes that a Seebeck voltage $V_{S}$ appears. If the circuit is closed by a certain 
resistive load $R_{L}$, the voltage $V_{S}$ forces a Peltier current $I$ flow, and in consequence there appears a Joule heat resulting from dissipated power in the internal resistance $R_{I}$ of the Peltier module. Joule heat introduces some temperature disturbance to the existing temperature gradient, and thus influences on the Seebeck voltage. Then the whole cycle starts again.

In order to derive quantitative description of the TEG operation a layered model will be analysed which is shown in Fig. 8. The passive elements of the TEG will be described by means of the general equation of heat conduction (7), while the active parts will be modeled according to the constant parameters theory (Buist, 1995).

$$
\lambda \nabla T(x, y, z, t)+w(x, y, z, t)=C_{\vartheta} \frac{\partial T(x, y, z, t)}{\partial t}
$$

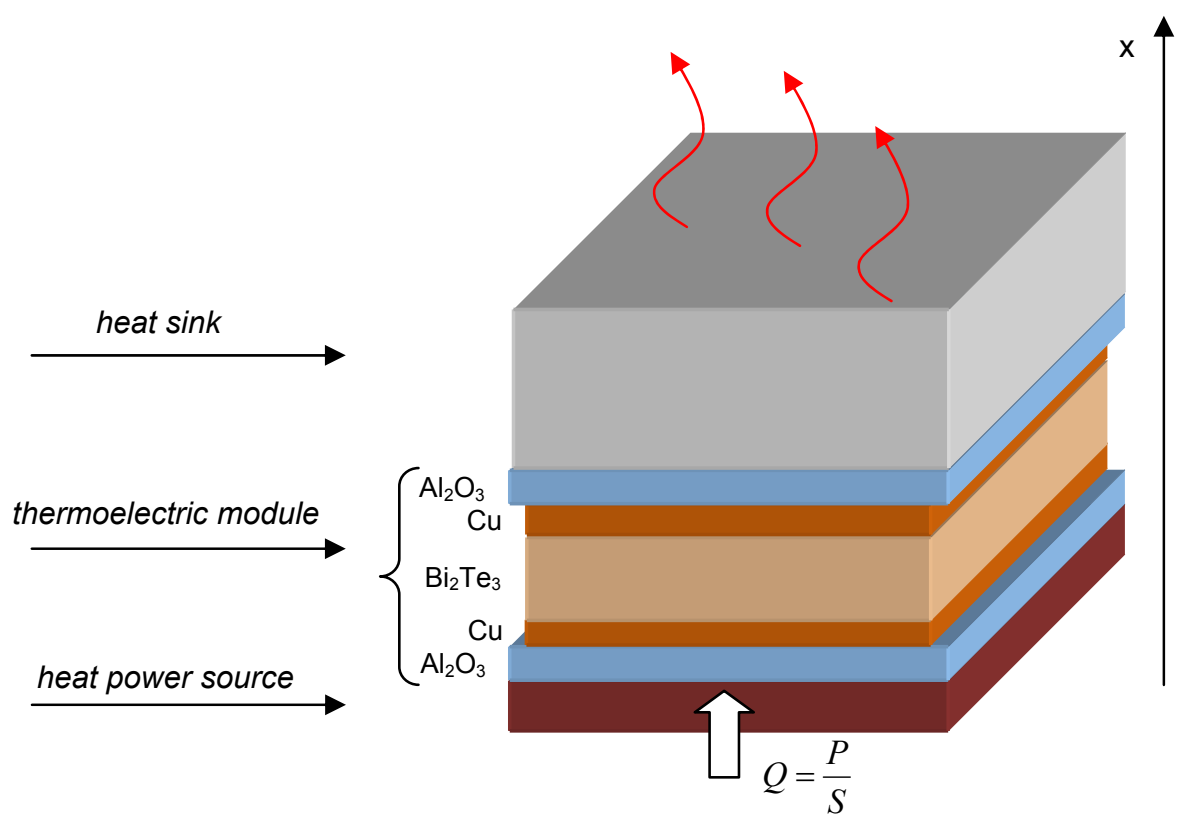

Fig. 8. Layered model of a thermoelectric generator subjected to analysis.

Where, $w$ is generated heat power density distribution, $\mathrm{C}_{\vartheta}$ is the specific heat capacity coefficient.

\subsection{Heat conduction in passive layers of a thermoelectric module}

With a good approximation it can be assumed one-directional heat flow due to much larger planar dimensions of the thermoelectric generator than the lateral ones. It means that the surfaces that are parallel to the direction of heat flow can be treated as adiabatic ones (8) (De Baetselier et al., 1995b). 


$$
\frac{\partial T(x, y, z)}{\partial y}=0, \quad \frac{\partial T(x, y, z)}{\partial z}=0
$$

Differential equation for a heat flow in a steady state, without internal heat sources, can be expressed by (9). In (10) and (11), boundary conditions for interfaces between heat source and $\mathrm{Al}_{2} \mathrm{O}_{3}$ as well as $\mathrm{Al}_{2} \mathrm{O}_{3}$ and copper strips are presented.

$$
\begin{gathered}
\frac{d^{2} T}{d x^{2}}=0 \\
\left.\frac{d T}{d x}\right|_{x=0}=\frac{P}{S_{\mathrm{Al}_{2} \mathrm{O}_{3}} \cdot \lambda_{\mathrm{Al}_{2} \mathrm{O}_{3}}} \\
\left.\lambda_{\mathrm{Al}_{2} \mathrm{O}_{3}} \frac{d T_{\mathrm{Al}_{2} \mathrm{O}_{3}}(x)}{d x}\right|_{x=l_{\mathrm{Al}_{2} \mathrm{O}_{3}}}=\left.\lambda_{\mathrm{Cu}} \frac{d T_{\mathrm{Cu}}(x)}{d x}\right|_{x=0}
\end{gathered}
$$

Finally, for the galvanic connection between copper layer and the cold side of the bismuth telluride, the temperature is equal to $T_{h}$ - temperature of the hot side of the active part of the TEG (12).

$$
\left.T_{C u}(x)\right|_{x=l_{C u}}=T_{h}
$$

For the opposite side of the thermoelectric modules we can derive similar equations, except that the $\mathrm{Al}_{2} \mathrm{O}_{3}$ layer at the cold surface is adjacent to a heat sink (13).

$$
\left.\lambda_{\mathrm{Al}_{2} \mathrm{O}_{3}} \frac{d \mathrm{~T}_{\mathrm{Al}_{2} \mathrm{O}_{3}}(x)}{d x}\right|_{x=l_{\mathrm{Al}_{2} \mathrm{O}_{3}}}=\left.\lambda_{h s} \frac{d T_{h s}(x)}{d x}\right|_{x=0}
$$

The other side of the heat sink is exposed to an ambient temperature Ta. The heat is transferred to the surrounding environment by radiation and convection which are described by the average heat transfer coefficient $h(14)$ (Kos, 1994).

$$
\left.\frac{d T}{d x}\right|_{x=h s}=-\frac{\bar{h}}{\lambda_{h s}}\left(T_{h s}-T_{a}\right)
$$

\subsection{Heat flow and power generation in active part of a thermoelectric module}

According to the thermoelectric theory based on constant parameters the active part of a thermoelectric generator can be described by a set of three equations. Two of them are relating to the thermal domain and represent heat powers $Q_{c}$ at the cold side (15), and $Q_{h}$ at the hot one (16), while the last one comes from the electrical domain and represents an electrical circuit consisting of an electromotive force $V_{S}$ causing a Peltier current $I$ flow (17). 


$$
\begin{gathered}
Q_{c}=\alpha_{B i_{2} T e_{3}}(T) \cdot T_{c} \cdot I-\frac{I^{2} \cdot R_{B_{2} T e_{3}}(T)}{2}-K_{B i_{2} T e_{3}}(T) \cdot\left(T_{h}-T_{c}\right)=Q_{c 1}-Q_{c 2}-Q_{c 3} \\
Q_{h}=\alpha_{B i_{2} T e_{3}}(T) \cdot T_{h} \cdot I+\frac{I^{2} \cdot R_{B_{2} T e_{3}}(T)}{2}-K_{B i_{2} T e_{3}}(T) \cdot\left(T_{h}-T_{c}\right)=Q_{h 1}+Q_{h 2}-Q_{h 3} \\
V_{S}=\left[\alpha_{B i_{2} T e_{3}}(T) \cdot T_{h}-\alpha_{B i_{2} T e_{3}}(T) \cdot T_{c}\right]
\end{gathered}
$$

Neglecting the Thomson effect, the thermoelectric device can be shown as two heat power generators (Fig. 9) consisting of components responsible for Peltier effect $Q_{c 1}$ and $Q_{h 1}$, Joule heat $Q_{c 2}$ and $Q_{h 2}$, heat conduction $Q_{c 3}$ and $Q_{h 3}$. In case of the Joule heat it is assumed that one half of it dissipates at the cold side and the other half flows to the other side of the thermoelectric generator.
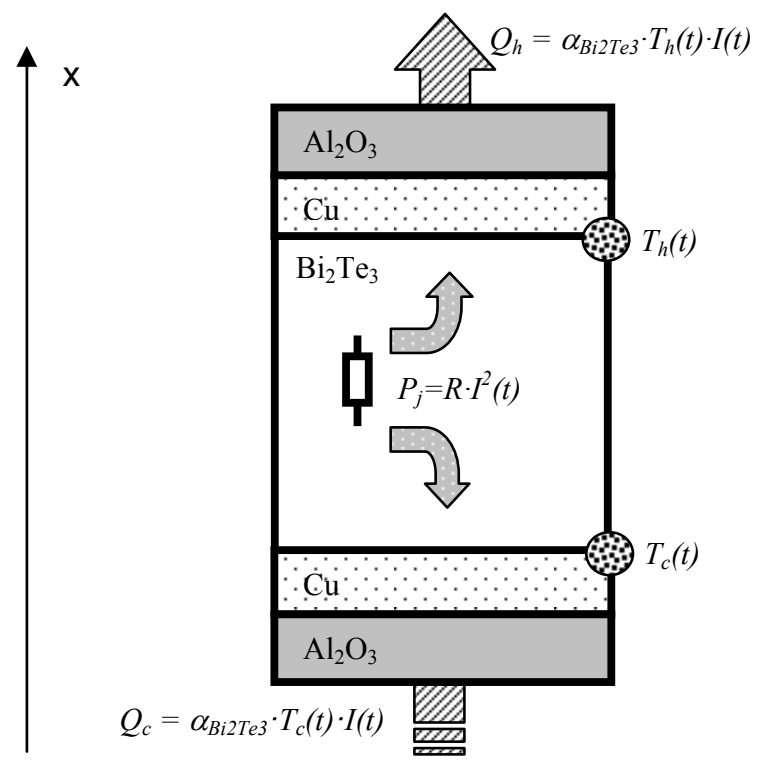

Fig. 9. Cross section of the active part of a Peltier module with two heat power generators.

\section{Electrothermal model of thermoelectric generator based on Peltier modules}

Complexity of the electrothermal behaviour of thermoelectric devices - that is described by nonlinear differential equations - can be represented and solved by means of finite element modeling (FEM). However, such a sophisticated tool is impractical from the electronic engineers' point of view who need intuitively easy to understand and user friendly simulators.

An electrothermal model of a TEG based on Peltier module makes possible for engineers to carry out investigations - not necessarily going into physical details - on free power 
generators converting some available ambient energy. To properly model electro-thermal phenomena in SPICE-like simulators the well known analogy has to be used, where: temperature $T$ corresponds to electrical voltage $V$, heat flux $Q$ to electrical current $I$, and thermal resistance $R_{t h}$ to electrical resistance $R$.

Due to the fact that the SPICE-like simulators are dedicated to simulations of only electric phenomena, the whole synthesised equivalent circuit representing all the physical aspects of a TEG operation has to be separated into two different circuits: one representing thermal phenomena and the other for electrical ones (Fig. 10). These two circuits are in mutual interaction by exchanging information about generated heat flux $Q$ and changing temperature $T$. The real electrical circuit represents an electromotive force the $V_{S}$ that causes a Peltier current flow and in consequence Joule heat generation. The heat flux $Q$ is converted into thermal domain by means of an auxiliary thermal circuit and influences on the operation of the thermal model of the TEG that is represented by a real thermal circuit. Next, it introduces some changes in temperature distribution which in turn, by means of an auxiliary electrical circuit, modifies the Seebeck voltage. By means of the electrothermal analogy, only equivalent electrical elements are needed to be used for modelling of heat conduction as well as power heat generation.

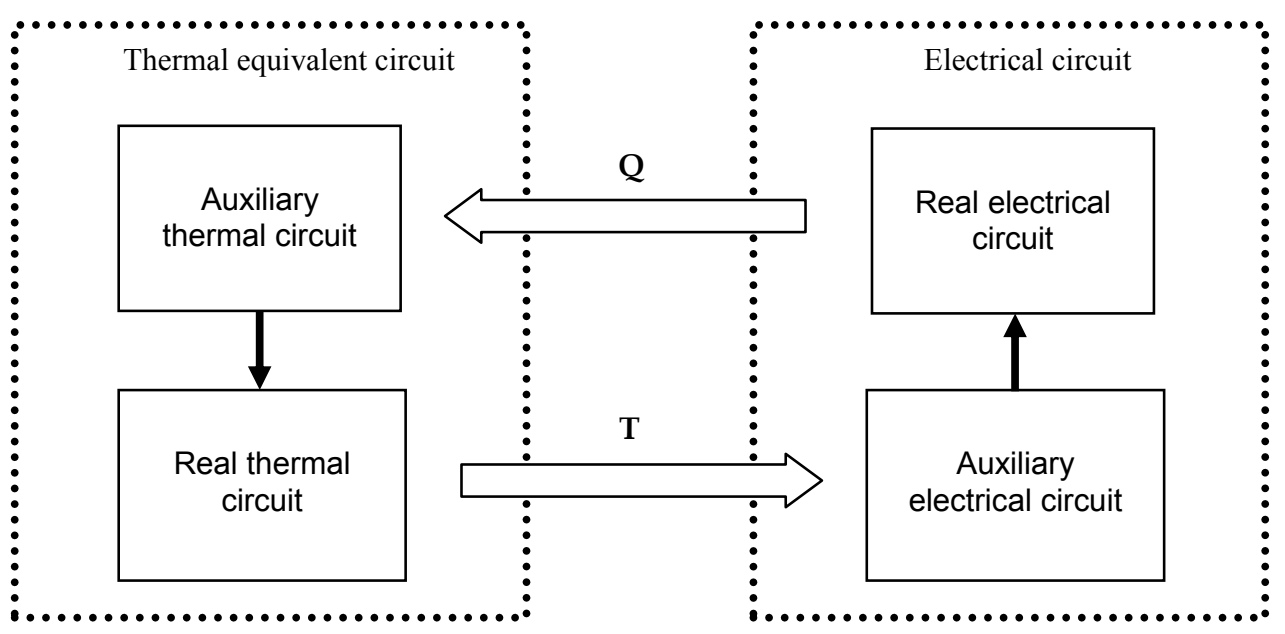

Fig. 10. Block diagram illustrating interaction between the electrical circuit and the thermal equivalent circuit.

\subsection{Synthesis of the equivalent electrothermal model of a TEG}

By solving the set of equations (9)-(12) describing heat conduction in passive layers of the TEG, the formulas for the hot and cold sides respectively are obtained in (18) and (19) (Janke, 1992). They can be treated as Kirchhoff's law in thermal domain.

$$
T_{\text {heat_source }}=T_{h}+P\left(\frac{l_{\mathrm{Al}_{2} \mathrm{O}_{3}}}{S_{\mathrm{Al}_{2} \mathrm{O}_{3}} \cdot \lambda_{\mathrm{Al}_{2} \mathrm{O}_{3}}}+\frac{l_{\mathrm{Cu}}}{S_{\mathrm{Cu}} \cdot \lambda_{\mathrm{Cu}}}\right)=T_{h}+P\left(R_{t_{-} \mathrm{Al}_{2} \mathrm{O}_{3}}+R_{\text {th_ }} \mathrm{Cu}\right)
$$




$$
T_{c}=T_{a}+Q_{c}\left(R_{t h \_h s}+R_{t h \_A l_{2} O_{3}}+R_{t h \_} C u\right)
$$

$R_{\text {th_hs }}$ is the thermal resistance represented by a heat sink and it takes into account heat conduction, convection as well as radiation (20).

$$
R_{t h \_h s}=\frac{l_{h s}}{S_{h s} \cdot \lambda_{h s}}+\frac{1}{h \cdot S_{h s}}
$$

Appropriate model should also describe the behaviour of the TEG in transient states. For this purpose a concept of thermal capacity $C_{t h}$ is introduced. Interpretation of the thermal capacity is obtained by comparing the temperature impulse response characteristics for a single layer with the analytical solution of this problem. As a result, the thermal capacity for a single layer can be expressed as in (21) (Janke, 1992).

$$
C_{t h}=\frac{\tau}{R_{t h}}=\frac{4 \cdot C_{\vartheta} \cdot l \cdot S}{\pi^{2}}
$$

From equations (18)-(21) one can easily derive equivalent passive elements of the TEG that form an equivalent circuit. After connection the active heat power sources and Seebeck voltage described in (15)-(17) a complete model is obtained (Fig. 11).

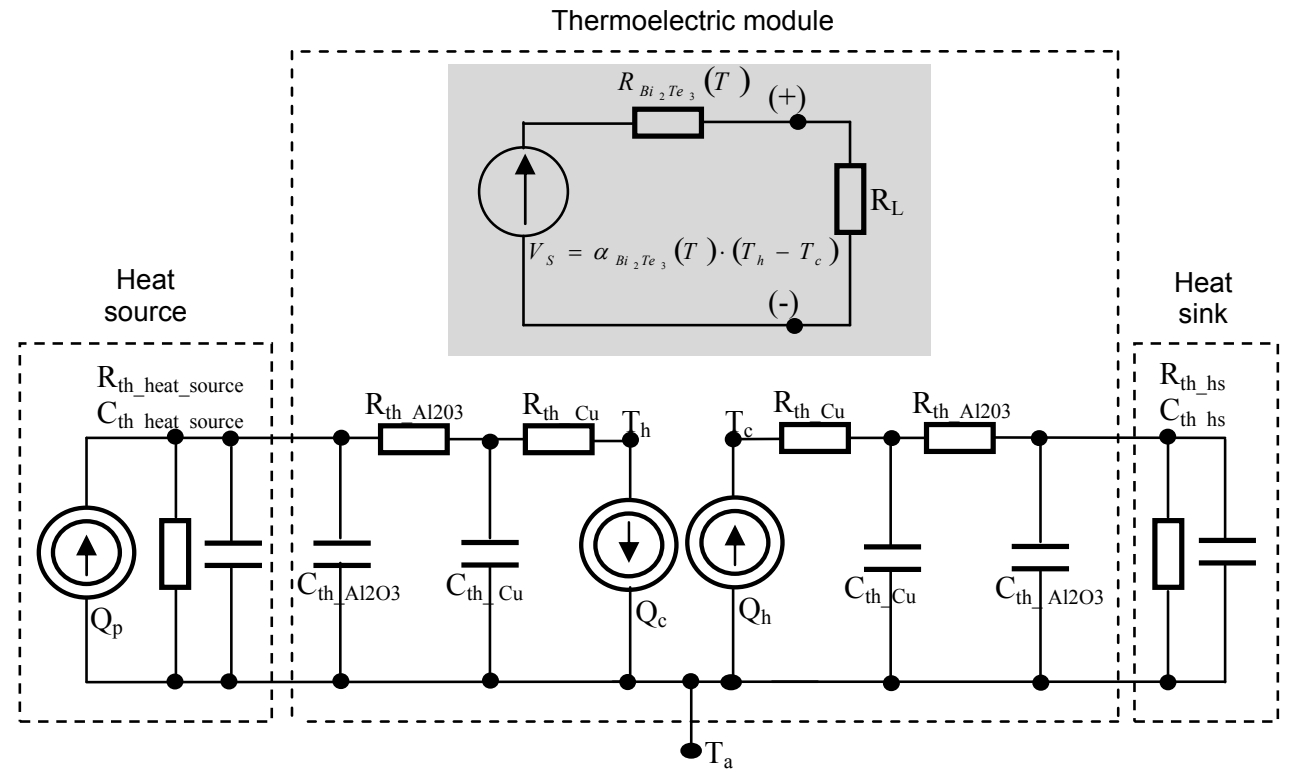

Fig. 11. Complete equivalent electrothermal model of a thermoelectric generator.

The final model of the TEG was converted to a netlist and implemented into electronic circuits simulator. To get products of some quantities that constitute $Q_{c}, Q_{h}$ and $V_{s}$, auxiliary voltage dependent current sources were used. 
Gamc 011 POLY(1) 1000 11.03m 28.6u -188n

Rtym_amc 1101

Gqc1 100500 POLY(3) 11011003000000000000000001

Grmc 022 POLY(1) $1000352 \mathrm{~m} 1.7 \mathrm{~m}$

Rtym_rmc 2201

Gqc2 500100 POLY(2) 2203000000000000.5

Gkmc 033 POLY(1) 1000 174m 290u 7.25u

Rtym_kmc 3301

Gqc3 500100 POLY(3) $33020001000000001-1$

Fig. 12. A part of a SPICE notation describing the cold heat power source.

In the SPICE notation, the final model of the TEG is seen as a subcircuit consisting of four terminals, as shown in Fig. 13.

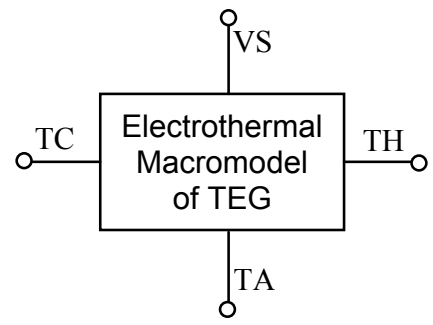

Fig. 13. Macromodel of TEG.

Nodes TC and TH represent temperatures in ${ }^{\circ} \mathrm{C}$ at the cold and hot sides respectively, while TA refers to an ambient temperature. These three input terminals come from thermal equivalent circuit and during simulations in SPICE they are seen as voltages. They can be connected to the voltage sources (any function) and then the conditions would be similar to those as the TEG was placed between two objects of infinite thermal capacity. They can also be connected to the passive thermal circuits or the heat sources, of any time functions, that are represented in equivalent circuits by current sources. The terminal VS comes from electrical part of the model. It is the output node where Seebeck voltage appears. It can be connected to any kind of a resistive load to simulate real conditions of energy harvesting processes.

\subsection{Improved electrothermal model}

Assumption about constant parameters $a, R, K$ seems to be a simplified solution in view of the temperature range the TEG is going to work in, and because of the actual temperature dependency of the parameters, because they show strong nonlinear temperature dependency as it was presented in Fig. 3 - Fig. 5. In typical working conditions, common in the industrial environment, for temperatures ranging from $-20^{\circ} \mathrm{C}$ to $120^{\circ} \mathrm{C}$, the parameters can change their values from $13 \%$ (for $a$ ) beyond $80 \%$ (for $K$ )! 
To increase the accuracy of the model some modifications were made. Among others, the dependencies of the coefficients: $\alpha, R, K$, on temperature were introduced. Their changes with temperature were taken into consideration and implemented into the model by approximation of polynomial second order functions. It was assumed that the temperature argument $T$ appearing in equations (15)-(17) should match the average temperature $T_{a v}$ between the two sides of the thermoelectric module (Seifert et al., 2001).

\subsection{Experimental characterization of thermoelectric modules}

Unfortunately, temperature characteristics of the coefficients of thermoelectric modules are not disclosed to the users by manufacturers, as a general rule. Due to this fact, before they can be taken advantage of, in constructing of an electrothermal model, first they need to be calculated during experimental characterization processes.

Methodology for extracting thermoelectric module parameters can be found in the work (Mitrani et al., 2005). Slightly different approach was demonstrated by (Dalola et al., 2008).

To determine temperature dependences of Seebeck coefficient $a_{B i 2 T e 3}$ and electrical resistance of thermoelectric couples $R_{\text {Bi2Te3 }}$ the TEM under test should be placed between two objects of controlled in a wide range temperatures $T_{c}$ and $T_{h}$. From measured output voltage $V_{O}$ and electrical current $I$ the two parameters can be derived as in (22) and (23).

$$
\begin{aligned}
& \alpha_{B i_{2} T e_{3}}=\left.\frac{V_{O}}{T_{h}-T_{c}}\right|_{I=0} \\
& R_{B i_{2} T e_{3}}=\frac{\left.V_{O}\right|_{I=0}-V_{O}}{I}
\end{aligned}
$$

Experimental measurement of the thermal conductivity $K_{B i 2 T e 3}$ brings about much more problems because to its determination a heat flux $Q$ should be known. Therefore, some modification in measurement setup which is shown in Fig. 14 is necessary.

Temperature of the cold side of the thermoelectric module under test is controlled in a closed feedback loop by an auxiliary thermoelectric cooler. The other side of the module is fixed to an auxiliary heat conducting block made of aluminum or copper, with adiabatic surfaces. The other end of the block is fixed to an auxiliary TEM with controlled temperature $T_{x}$, which is higher than $T_{c}$. Provided that the thermal conductivity coefficient of the auxiliary conducting block is known, the heat flux is easily obtained as in (24).

$$
Q_{h}=Q_{x}=\lambda_{A l}\left(T_{h}-T_{c}\right)
$$

Taking into account the equation (14), thermal conductivity for bismuth telluride active part can be calculated as in (25).

$$
K_{B i_{2} T e_{3}}=\frac{\alpha_{B i_{2} T e_{3}} T_{h} I+0.5 I^{2} R_{B i_{2} T e_{3}}-\alpha_{A l}\left(T_{h}-T_{x}\right)}{T_{h}-T_{c}}
$$

The obtained temperature characteristics of the main three parameters are approximated by polynomial second order functions, which for the examined Peltier device were shown in 
Fig. 3 - Fig. 5. The coefficients staying before variables in the approximated functions are next introduced to the core netlist notation of the SPICE-like simulators.

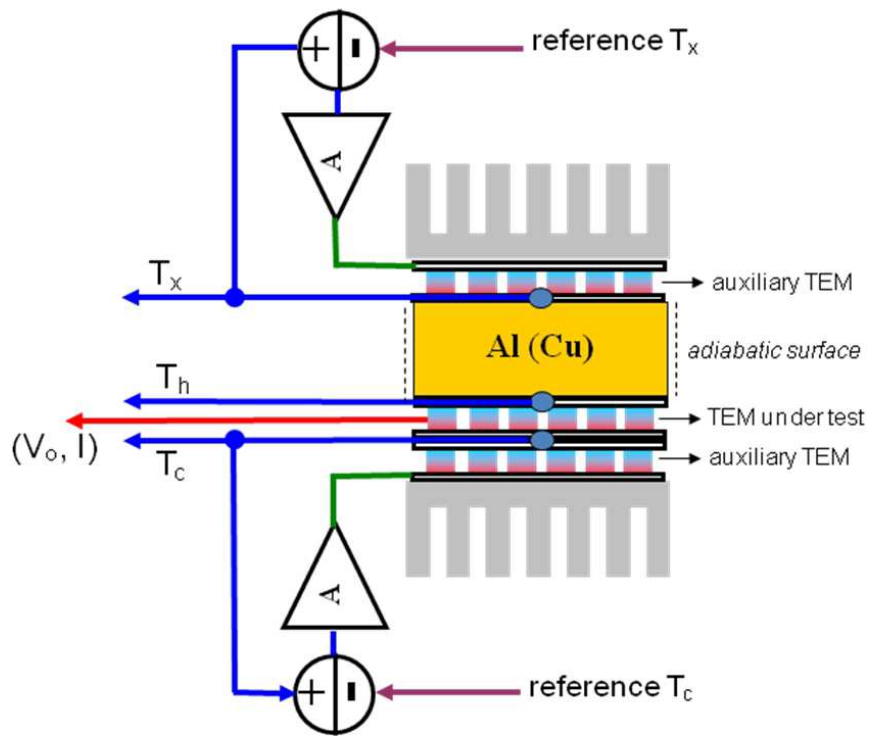

Fig. 14. Measurement setup for characterization of thermoelectric modules.

\section{Simulations of energy harvesting processes in thermoelectric generators}

The crucial part in the whole design process of TEGs is the modeling and electrothermal simulations which can provide good estimations of electrical energy that can be obtained from heat conversion. Properly designed generator requires many simulations during design stage against different conditions, so as to obtain as much as possible electrical energy from a relatively low efficiency system. In some cases it can replace prototyping of complex designs. The implemented macromodel of TEG into SPICE-like simulators makes possible to perform different simulation scenarios. In the next following examples some results of simulations experiments that were performed by means of the electrothermal model of TEG and electronic circuits simulator SPICE are presented. They give quantitative information about behaviour of the real TEG under different thermal and electrical conditions often occurring in practice. All the presented simulations were performed for a 127 pairs commercially available thermoelectric module for which the approximated polynomial functions look like in (26)-(28).

$$
\begin{gathered}
\alpha_{\mathrm{Bi}_{2} T e_{3}}(T)=-7 \cdot 10^{-7} T^{2}+1 \cdot 10^{-4} T+49.1 \cdot 10^{-3} \\
R_{B i_{2} T e_{3}}(T)=10.1 \cdot 10^{-3} T+1.98 \\
K_{B i_{2} T e_{3}}(T)=4 \cdot 10^{-5} T^{2}-2.2 \cdot 10^{-3} T+0.4626
\end{gathered}
$$




\subsection{Examples of simulations}

Output voltage $V_{S}$ from the TEG for $R_{L}=\infty$ is shown in the Fig. 15. The simulations were performed for different temperature gradients by setting $T_{c}$ as parameter and $T_{h}$ as an argument. A scheme of the equivalent circuit for the presented simulations is shown next to the characteristics.
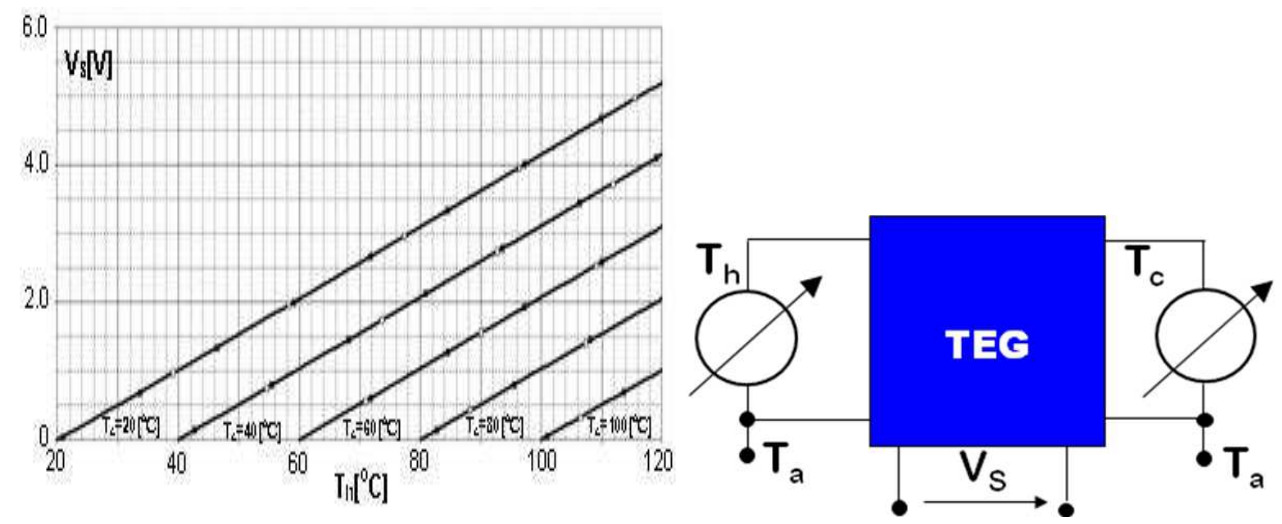

Fig. 15. Output voltage $V_{S}$ versus temperature of the hot side and constant $T_{C}$.

The graphs allow estimating maximum ratings of voltages when no resistive load is present. They can be very useful in the course of designing DC-DC boost regulators pushing up the voltage to the level required by an electronic circuitry, for example sensor nodes.

In the Fig. 16 an output power $P_{L}$ in relation to a resistive load $R_{L}$ and different temperature gradients $\Delta T$ is depicted. From the simulated functions one can find the points of the best matching between $R_{L}$ and the inner resistance of the Peltier module. It is worth mentioning that the maximum power transfer point (MPTP) is not constant but moves in the direction of higher $R_{L}$ as the temperature gradient $\Delta T$ is increasing.
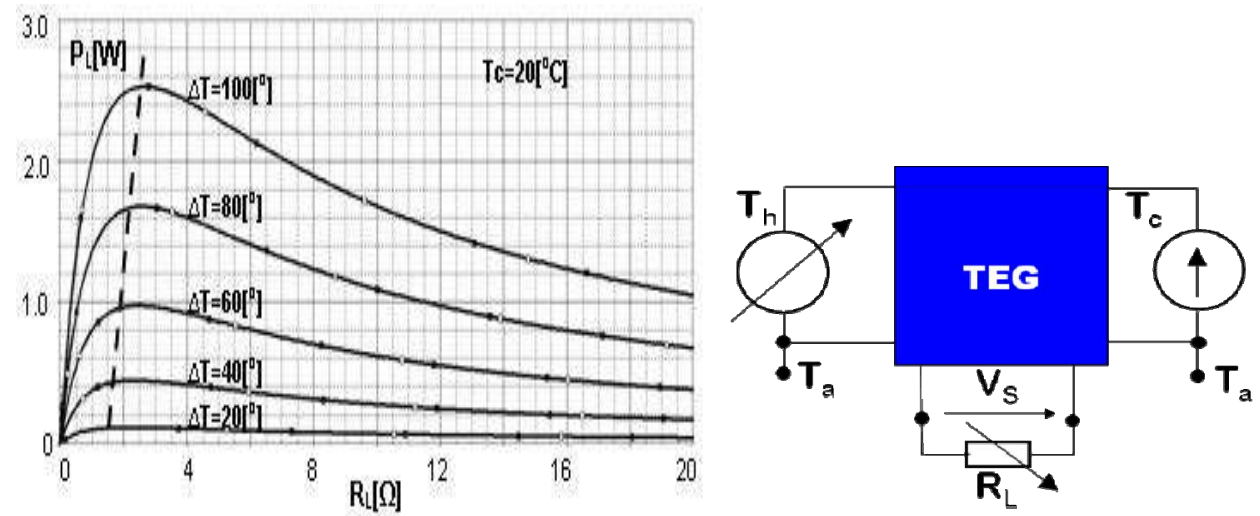

Fig. 16. Output power $P_{L}$ versus resistive load and constant temperature gradient $\Delta T$. 

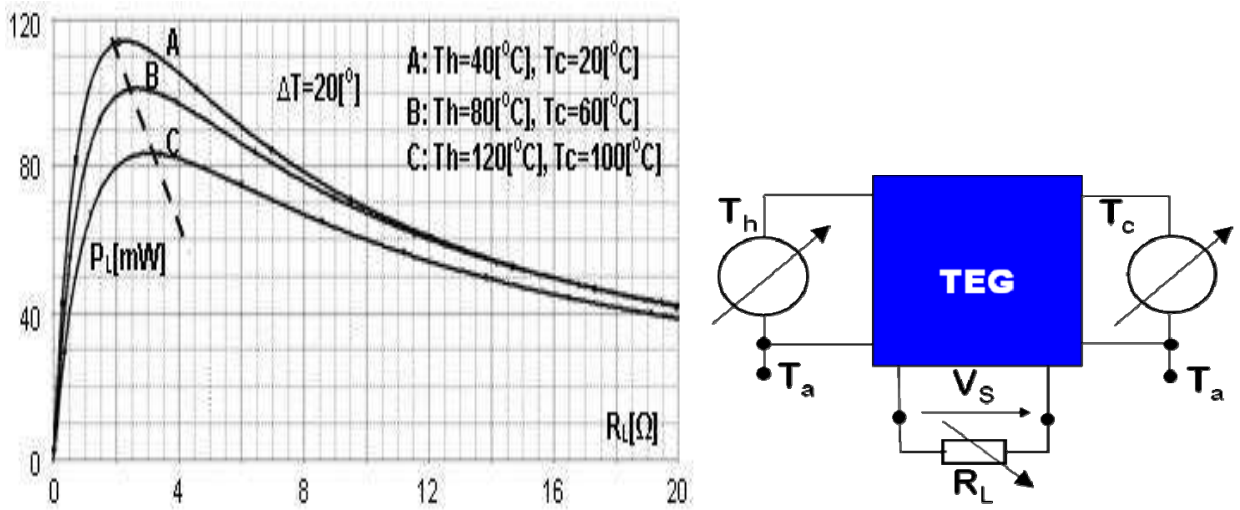

Fig. 17. Output power $P_{L}$ versus resistive load $R_{L}$ and the same temperature gradients $\Delta T$, located in low, medium and high temperatures.

Next, the Fig. 17 shows the output power $P_{L}$ in the function of $R_{L}$ for the same $\Delta T=20^{\circ}$, in low, medium and high temperatures. From this picture it is evident to designers that the maximum output power $P_{L}$ depends not only on $R_{L}$ and $\Delta T$, but also on the temperature range the $\Delta T$ gradient is located in.

Functions of coefficient of performance COP, defined as in (29), are shown in Fig. 18 and Fig 19. They both present conversion efficiency in relation to a resistive load $R_{L}$ and a heat power $Q_{h}$. It can be observed that COP does not exceed $12 \%$.

$$
\mathrm{COP}=\frac{P_{L}}{Q_{h}} \cdot 100 \%
$$

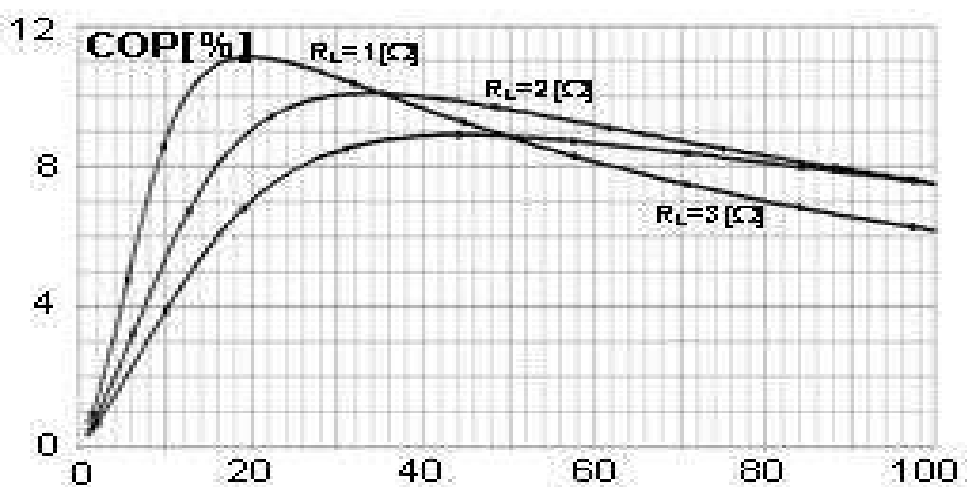

Fig. 18. Coefficient of performance COP versus heat power of the hot side and constant $R_{L}$.

Results presented in Fig. 20 illustrate importance of proper selection of the heat sink that is attached to the cold side of the module on the overall performance of TEG. From the point of view of the output voltage, it seems that the thermal resistance $R_{t h \_h s}$ of the heat sink should be chosen as low as possible, so that the high heat power $Q_{h}$ would resulted in a 
large enough temperature gradient across the Peltier module. Otherwise, too high $R_{\text {th_hs }}$ might squander the whole effort that was made to improve the overall system efficiency. On the other hand it can be proved that similarly to the idea of electrical matching, the maximum power transfer can be provided if the thermal resistance of the heat sink is matched with thermal resistance of the thermoelectric module.

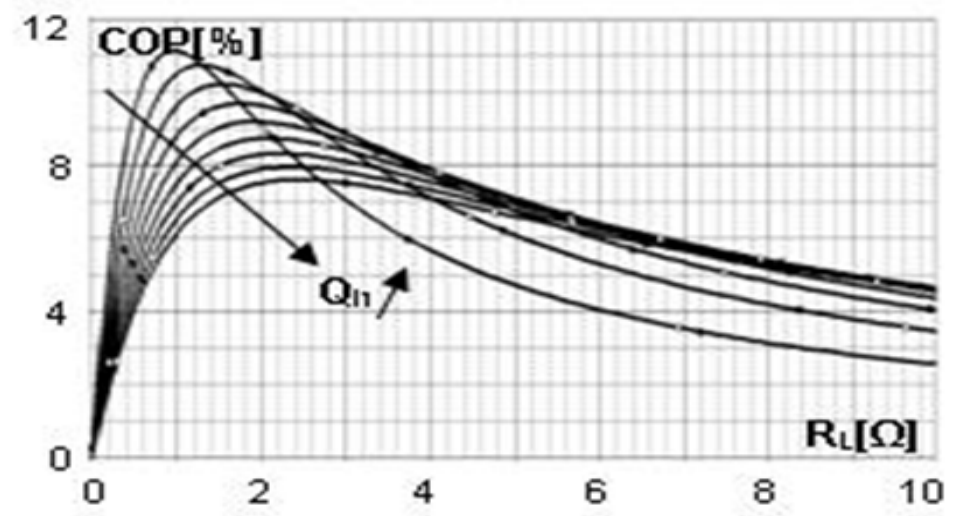

Fig. 19. Coefficient of performance COP versus resistive load $R_{L}$.
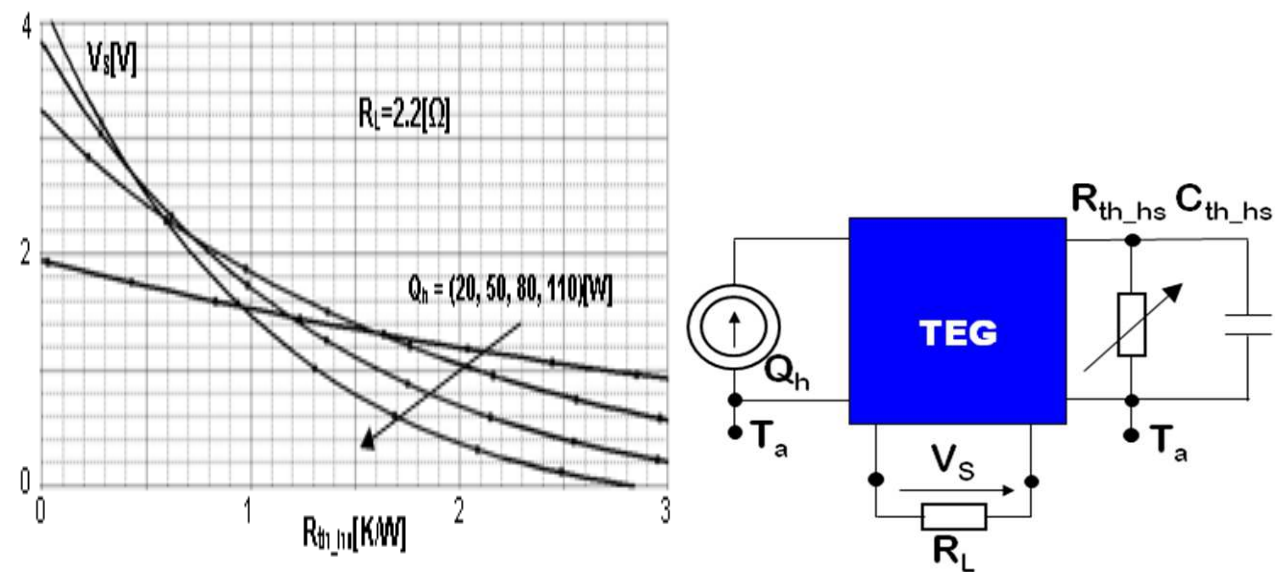

Fig. 20. Output voltage $V_{S}$ versus thermal resistance of a heat sink.

\section{Conclusion}

Thermoelectric generators fulfill a very important role in some niche applications, for example they provide energy for satellites and space equipment. Smaller TEGs can supply electrical energy to remote distant low power consumption objects and when there is no electricity nearby. Thermoelectric modules applied as electrical energy generators can be treated as potential sources of green energy, although as a matter of fact they suffer from relatively low efficiency so far. Hopefully, with new materials technology development TEGs will have better energy conversion coefficients of performance in the future. However, 
it is obvious that for energy harvesting applications Peltier devices can have a very high potential impact.

Presented electrothermal model took into account both thermal and electrical phenomena taking place in Peltier modules. The model is easy to adapt in any electronic circuits simulator, especially in SPICE which has well established position as convenient and reliable software among electronic engineers. The improved version of the model took also the temperature dependent coefficients, describing operation of the TEGs, into consideration, thus leading to its increased accuracy.

Obtained experimental simulations give a number of interesting insights into interactions between TEG, surrounding environment and the electrical load. In this way, they make possible to perform qualitative analysis of energy harvesting processes. They proved the usefulness of the model for designers of the real harvesters made of Peltier modules, thanks to the fact that the whole design process is then more cost effective and efficient.

Future research work will be focused on more accurate modeling of temperature functions of the crucial parameters. In fact the average temperature $T_{a v}$ that is used in the improved model for determining actual values of the coefficients should be calculated by integration of the nonlinear temperature profiles of coefficients along the pellets. This issue should be taken into account especially for high temperature gradients.

\section{Acknowledgement}

The work was supported by the National Centre for Research and Development (NCBiR) project grant No. R02 0073 06/2009.

\section{References}

Anatychuk L. I. (1995). Thermoelectrically Cooled Radiation Detectors, CRC Handbook of Thermoelectrics, CRC Press 1995, pp. 633-640.

Beeby S., White N. (2010). Energy Harvesting for Autonomous Systems, Artech House, 2010, ISBN-13: 978-1-59693-718-5.

Buist R. J. (1995). Calculation of Peltier device performance, CRC Handbook of Thermoelectrics, CRC Press 1995, pp. 143-155.

Chen M., Rosendahl L. A., Condra T. J., Pedersen J. K. (2009). Numerical Modeling of Thermoelectric Generators With Varing Material Properties in a Circuit Simulator, IEEE Transactions on Energy Conversion, Vol. 24, No. 1, March 2009, pp. 112-124.

Dalola S., Ferrari M., Ferrari V., Guizzetti D. M., Taroni A. (2008). Characterization of Thermoelectric Modules for Powering Autonomous Sensors, IEEE Transactions on Instrumentation and Measurement, Vol. 58, No. 1, January 2009, pp. 99-107.

De Baetselier E., De Mey G., Kos A. (1995a). Thermal Image Generator as a Vision Prosthesis for the Blind, MST Poland News, No. 3(7), October 1997, pp. 3-5.

De Baetselier E., Goedertier W., De Mey G. (1995b). Thermoregulation of IC's with high power dissipation, Proceedings of the 10th European hybrid Microelectronics Conference, Copenhagen, Denmark, May 1995, ISHM, pp. 425-439.

Dziurdzia P., Kos A. (1999). Electrothermal Macromodel of Active Heat Sink for Cooling Process Simulation, Proc. of the 5-th International Workshop on Thermal Investigations of Ics and Microstructures, Roma, Italy, October 4-6, 1999, pp.76-81. 
Dziurdzia P., Kos A. (2000). High Efficiency Active Cooling System, Proceedings. of the XVIth Annual IEEE Semiconductor Thermal Measurement and Management Symposium SEMITHERM, San Jose, USA, 21-23 March 2000, pp. 19-26.

Freunek M., Muller M., Ungan T., Walker W., Reindl L. M. (2009). New Physical Model for Thermoelectric Generators, Journal of Electronic Materials, Vol. 38, No. 7, 2009, pp. 1214-1220.

Janke W. (1992). Zjawiska termiczne w elementach i układach półprzewodnikowych, Układy i systemy elektroniczne, Wydawnictwa Naukowo - Techniczne, Warszawa 1992.

Joseph A. D. (2005). Energy Harvesting Projects, Published by the IEEE CS and IEEE ComSoc, 1536-1268/05.

Kos A. (1995). Modelowanie hybrydowych układów mocy i optymalizacja ich konstrukcji ze względu na rozkład temperatury, Rozprawy Monografie, Wydawnictwa AGH, Kraków 1994.

Kotanagi S. et al. (1999). Watch Provided with Thermoelectric Generator Unit, Patent No. WO/1999/019775.

Lineykin S., Ben-Yaakov S. (2005). Analysis of thermoelectric coolers by a spice-compatible equivalent-circuit model, Power Electronics Letter IEEE, Volume 3, Issue 2, 2005, pp. 63-66.

Lovell M. C., Avery A. J., Vernon M. W. (19821). Physical properties of materials, Van Nostrand Reinhold Company, University Press, Cambridge 1981.

Luo J., Chen Y., Tang K., Luo J. (2009). Remote monitoring information system and its applications based on the Internet of Things, BioMedical Information Engineering, 2009. FBIE 2009. International Conference on Future, 13-14 Dec. 2009, pp.482-485.

Mateu L., Codrea C., Lucas N., Pollak M., Spies P. (2007). Human Body Energy Harvesting Thermogenerator for Sensing Applications, Proc. of the International Conference on Sensor Technologies and Applications SensorComm 2007, October, Valencia, Spain, pp. 366-372.

McNaughton A. G. (1995). Commercially Available Generators, CRC Handbook of Thermoelectrics, CRC Press 1995, pp. 659-469.

Mitrani D., Tome J. A., Salazar J., Turo A., Garcia M. J., Chavez A. (2005). Methodology for Extracting Thermoelectric Module Parameters, IEEE Transactions on Instrumentation and Measurement, Vol. 54, No. 4, August 2005, pp. 1548-1552.

Paradiso J. A., Starner T. (2005). Energy Scavenging for Mobile and Wireless Electronics, Pervasive Computing, IEEE, Jan.-March 2005, pp. 18-27.

Penn A. (1974). Small electrical power sources, Phys. Technol, 5, 114,1974.

Priya S., Inman D. J. (2009). Energy Harvesting Technologies, Springer, 2009, ISBN 978-0-38776463-4.

Redstall R. M., Studd R. (1995). Reliability of Peltier Coolers in Fiber-Optic Laser Packages, CRC Handbook of Thermoelectrics, CRC Press 1995, pp. 641-645.

Salerno D. (2010). Ultralow Voltage Energy Harvester Uses Thermoeletric Generator for Battery-free Wireless Sensors, LT Journal, 2010, pp. 1-11.

Seifert W., Ueltzen M., Strumpel C., Heiliger W., Muller E. (2001). One-Dimensional Modeling of a Peltier Element, Proc. of the $20^{\text {th }}$ International Conference on Thermoelectrics, 2001.

Uemura K. (1995). Laboratory Equipment, CRC Handbook of Thermoelectrics, CRC Press 1995, pp. 647-655.

Wey T. (2006). On the Behavioral Modeling of a Thermoelectric Cooler and Mechanical Assembly, IEEE North-East Workshop on Circuit and Systems, 2006, pp. 277-280. 


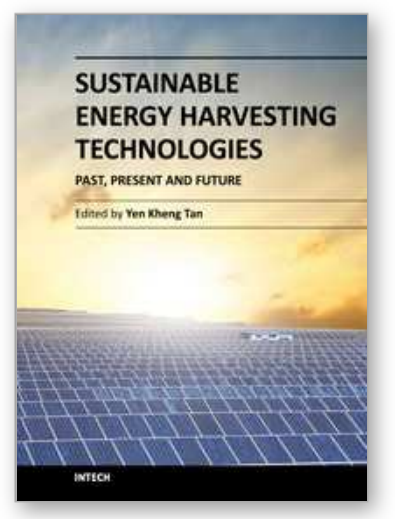

\author{
Sustainable Energy Harvesting Technologies - Past, Present and \\ Future \\ Edited by Dr. Yen Kheng Tan
}

ISBN 978-953-307-438-2

Hard cover, 256 pages

Publisher InTech

Published online 22, December, 2011

Published in print edition December, 2011

In the early 21 st century, research and development of sustainable energy harvesting $(\mathrm{EH})$ technologies have started. Since then, many EH technologies have evolved, advanced and even been successfully developed into hardware prototypes for sustaining the operational lifetime of low?power electronic devices like mobile gadgets, smart wireless sensor networks, etc. Energy harvesting is a technology that harvests freely available renewable energy from the ambient environment to recharge or put used energy back into the energy storage devices without the hassle of disrupting or even discontinuing the normal operation of the specific application. With the prior knowledge and experience developed over a decade ago, progress of sustainable $\mathrm{EH}$ technologies research is still intact and ongoing. EH technologies are starting to mature and strong synergies are formulating with dedicate application areas. To move forward, now would be a good time to setup a review and brainstorm session to evaluate the past, investigate and think through the present and understand and plan for the future sustainable energy harvesting technologies.

\title{
How to reference
}

In order to correctly reference this scholarly work, feel free to copy and paste the following:

Piotr Dziurdzia (2011). Modeling and Simulation of Thermoelectric Energy Harvesting Processes, Sustainable Energy Harvesting Technologies - Past, Present and Future, Dr. Yen Kheng Tan (Ed.), ISBN: 978-953-307438-2, InTech, Available from: http://www.intechopen.com/books/sustainable-energy-harvesting-technologiespast-present-and-future/modeling-and-simulation-of-thermoelectric-energy-harvesting-processes

\section{INTECH}

open science | open minds

\section{InTech Europe}

University Campus STeP Ri

Slavka Krautzeka 83/A

51000 Rijeka, Croatia

Phone: +385 (51) 770447

Fax: +385 (51) 686166

www.intechopen.com

\section{InTech China}

Unit 405, Office Block, Hotel Equatorial Shanghai

No.65, Yan An Road (West), Shanghai, 200040, China

中国上海市延安西路65号上海国际贵都大饭店办公楼 405 单元

Phone: +86-21-62489820

Fax: $+86-21-62489821$ 
(C) 2011 The Author(s). Licensee IntechOpen. This is an open access article distributed under the terms of the Creative Commons Attribution 3.0 License, which permits unrestricted use, distribution, and reproduction in any medium, provided the original work is properly cited. 